\title{
Mechanism of Hypertriglyceridaemia in Diabetic Patients with Fasting Hyperglycaemia
}

\author{
M. Greenfield, O. Kolterman, J. Olefsky, and G. M. Reaven \\ Department of Medicine, Stanford University School of Medicine, and Geriatric Research, Education, and Clinical Center, \\ Veterans Administration Medical Center, Palo Alto, California, USA
}

Summary. Several aspects of lipid metabolism were studied to define the mechanism of hypertriglyceridaemia in insulin-independent diabetic patients with fasting hyperglycaemia. Patients with insulinindependent diabetes were more obese $(\mathrm{p}<0.001)$ and had a significantly $(\mathrm{p}<0.001)$ higher mean $( \pm$ SEM) fasting plasma triglyceride concentration (387 $\pm 66 \mathrm{mg} / \mathrm{dl})$ than did either insulin-dependent diabetics $(133 \pm 11 \mathrm{mg} / \mathrm{dl})$ or normal $(73 \pm 1 \mathrm{mg} / \mathrm{dl})$ subjects. Very low density lipoprotein secretion rate was also significantly $(p<0.01-<0.001)$ higher in patients with insulin-independent diabetes (14.65 \pm $1.37 \mathrm{mg} / \mathrm{kg} / \mathrm{h}$ ) as compared to $7.64 \pm 0.60 \mathrm{mg} \cdot \mathrm{kg} / \mathrm{h}$ and $9.86 \pm 0.75 \mathrm{mg} / \mathrm{kg} / \mathrm{h}$ in normal subjects and patients with insulin-dependent diabetes, respectively. However, the relationship between plasma triglyceride concentration and very low density lipoprotein-triglyceride secretion was similar in diabetics and in normals. The diabetic groups had equivalent degrees of fasting and postprandial hyperglycaemia, and comparable elevations of fasting plasma nonesterified free fatty acid levels (insulin-independent $=0.72 \pm 0.07 \mathrm{mmol} / \mathrm{L}$, insulin-dependent $=0.63 \pm$ $0.08 \mathrm{mmol} / \mathrm{L}$ ). Postprandial plasma insulin concentrations, however, reached normal levels in insulinindependent diabetics and were higher $(p<0.001)$ than in insulin-dependent diabetics. Thus, hypertriglyceridaemia in insulin-independent diabetics with fasting hyperglycaemia was associated with increased hepatic very low density lipoprotein-triglyceride secretion, and normal plasma insulin levels. The lower triglyceride levels in the insulin-dependent diabetics is assumed to be due to their relative hypoinsulinaemia.

Key words: Hypertriglyceridaemia, fasting hyperglycaemia, insulin, diabetic hypertriglyceridaemia, glucose, insulin-independent diabetes, very low density lipoprotein secretion rate, triglycerides, insulindependent diabetes, non-esterified fatty acids.
Although the association between diabetes and hypertriglyceridaemia is well-recognised [1], it has become increasingly apparent that the relationship is complex. Three distinct clinical syndromes seem to exist. Hypertriglyceridaemia in patients with minimal abnormalities of glucose tolerance occurs in conjunction with loss of normal insulin sensitivity, and is characterised by hyperinsulinaemia and increased very low density lipoprotein triglyceride (VLDL-TG) secretion [2-4]. It has been suggested in this case that elevated plasma triglyceride concentrations are secondary to insulin-stimulated increases in hepatic VLDL-TG secretion [2-4]. At the other end of the spectrum are subjects with absolute insulin deficiency, in which hypertriglyceridaemia is probably due to defective VLDL-TG removal from plasma, secondary to an absolute lack of insulin [5-9]. The third clinical syndrome involves hypertriglyceridaemia in insulin-independent patients with fasting hyperglycaemia, and the cause of the hypertriglyceridaemia in these patients is uncertain. Direct measurements of VLDL-TG secretion rate suggest that the hypertriglyceridaemia is secondary to increased VLDL-TG secretion [10-13]. On the other hand, decreased adipose tissue lipoprotein lipase activity has been reported in such patients, leading to the suggestion that a defect in VLDL-TG removal from plasma is responsible for the elevated triglyceride levels [14]. The study to be described was carried out in order to clarify these mechanisms in insulin-independent diabetic patients in comparison with both normal subjects and insulin-dependent diabetic patients.

\section{Materials and Methods}

\section{Experimental Subjects}

Two groups of diabetic patients were selected for this study. The first group consisted of 22 patients with insulin-independent diabetes. Six of these individuals had received chlorpropamide in the 
Table 1. Clinical characteristics

\begin{tabular}{lccccc}
\hline Group & $\mathrm{n}$ & Age & Sex & $\begin{array}{l}\text { Relative } \\
\text { weight }^{\mathrm{a}}\end{array}$ & $\begin{array}{l}\text { Duration } \\
\text { of diabetes } \\
\text { (years) }\end{array}$ \\
\hline $\begin{array}{l}\text { Control } \\
\begin{array}{l}\text { Insulin- } \\
\text { dependent }\end{array}\end{array}$ & 15 & $41 \pm 4$ & $6 \mathrm{M}: 9 \mathrm{~F}$ & $0.98 \pm 0.03$ & - \\
$\begin{array}{l}\text { Insulin- } \\
\text { independent }\end{array}$ & 22 & $48 \pm 2$ & $11 \mathrm{M}: 11 \mathrm{~F}$ & $1.31 \pm 0.06$ & $10 \pm 2$ \\
\hline
\end{tabular}

a Actual weight $\div$ " Ideal" weight, derived from Metropolitan Life Insurance Tables, 1959

Table 2. Plasma triglyceride concentration and VLDL-TG secretion rates in the three groups of subjects. Results are presented as Mean \pm SEM

\begin{tabular}{lccr}
\hline Group & $\mathrm{n}$ & $\begin{array}{l}\text { Plasma } \\
\text { triglyceride } \\
(\mathrm{mg} / \mathrm{dl})\end{array}$ & \multicolumn{1}{l}{$\begin{array}{l}\text { VLDL-TG } \\
\text { secretion rate } \\
(\mathrm{mg} / \mathrm{kg} / \mathrm{h})\end{array}$} \\
\hline Control & 15 & $73 \pm 1$ & $7.64 \pm 0.60$ \\
Insulin-dependent & 17 & $133 \pm 11$ & $9.86 \pm 0.75$ \\
Insulin-independent & 22 & $387 \pm 66$ & $14.65 \pm 1.37$ \\
\hline
\end{tabular}

past, but treatment had been withdrawn at least three weeks prior to initiating the study. They had no known diseases other than diabetes, and received no medications. The other group consisted of 17 patients known to be insulin-dependent diabetics, without other known disease taking 20-80 Units of insulin/day (mean dose of $42 \mathrm{U} /$ day) without other medications. Criteria for inclusion in the study were fasting hyperglycaemia $(>150 \mathrm{mg} / \mathrm{dl})$, willingness to participate, and absence of any other significant illness known to affect carbohydrate and lipid metabolism. The latter criteria was achieved by a screening procedure which included a medical history, physical examination biochemical screen, electrocardiogram and chest X-ray. Patients were not selected on the basis of fasting triglyceride concentrations, and there was no family history of lipid abnormality among the participants. In addition, serum creatinine concentrations were within normal limits in all subjects, and proteinuria was not noted. Finally, 15 normal volunteers were studied concurrently. The protocol was approved by the Human Subjects Committee, and informed consent was obtained from all participants.

Table 1 shows that the insulin-dependent patients were younger than the insulin-independent subjects ( $p<0.02$ ), although the ranges overlapped (20-50 and 21-65 years, respectively). Insulin-dependent patients were also less obese $(\mathrm{p}<$ $0.001)$ than the insulin-independent group. Duration of diabetes was not significantly different between the two groups of patients.

\section{Experimental Protocol}

Subjects were hospitalised for the study. Insulin-dependent patients were continued on their previous insulin. All subjects were fed an isocaloric liquid formula diet $(35 \mathrm{Kcal} / \mathrm{kg}$ ) containing (as \% of calories) $43 \%$ carbohydrate, $42 \%$ fat, and $15 \%$ protein as previously described $[3,4]$. The formula was divided into portions of $1 / 5,2 / 5$ and $2 / 5$, consumed over approximately $30 \mathrm{~min}$ at $0800 \mathrm{~h}$, $1200 \mathrm{~h}$ and $1800 \mathrm{~h}$. The patients were maintained on the diet for a period of 10-14 days. After a period of 4 days, daily fasting blood samples were obtained for determination of plasma glucose [15], non-esterified fatty acids [16], and triglyceride concentrations [17]. Free insulin concentrations were determined in all patients following preliminary polyethylene glycol precipitation to remove insulin antibodies [18] by a modification of the method of Desbuquois and Aurbach [19].

a. Meal Tolerance Tests. Plasma glucose, insulin, and nonesterified fatty acid responses to the $1200 \mathrm{~h}$ meal were determined on three occasions during the last week of the study. Blood was drawn at $1200 \mathrm{~h}$, before the meal, and then at $1230,1300,1400$ and $1500 \mathrm{~h}$. Mean values for all three tests were calculated for each subject.

b. VLDL-TG Turnover Rate. VLDL-TG turnover rate was estimated by a modification [20] of our earlier method [21]. Patients received $300 \mu \mathrm{Ci}$ of ${ }^{3} \mathrm{H}$-glycerol intravenously, at $0800 \mathrm{~h}$, and blood was drawn $1,2,4,6,9,12$ and $24 \mathrm{~h}$ later. Subjects received $1 / 12$ th of the day's formula at 1400,1700 , and $2000 \mathrm{~h}$ in order to maintain plasma triglyceride levels steady throughout the $24 \mathrm{~h}$ period. Plasma was separated by centrifugation and aliquots were used for determination of plasma triglyceride concentration and for isolation of endogenously labeled VLDL-TG by extraction with chloroform-methanol $(2: 1, \mathrm{v} / \mathrm{v})$. Plasma triglyceride concentration was steady throughout the study (i. e., the coefficient of variation of the samples was less than $10 \%$ ); recovery of triglyceride radioactivity, checked with thin layer chromatography, was $90 \%$ or more; and contamination by other lipid fractions was less than $10 \%$. No fractionation of lipoproteins was carried out for reasons discussed previously [20].

The fractional turnover rate was determined by the formula, $\mathrm{k}=0.693 \div$ half-time of disappearance of labeled VLDL-TG from plasma from the first order time curves. Total VLDL-TG turnover rate was calculated from the formula:

$\mathrm{V}=0.45 \times \mathrm{k} \times \mathrm{S} \times \mathrm{b}$

where $\mathrm{V}$ is the total VLDL-TG turnover rate in $\mathrm{mg} / \mathrm{h} / \mathrm{kg}$ body weight and $\mathrm{S}$ is the plasma TG concentration. The coefficient 0.45 assumes that the plasma volume is $45 \mathrm{mg} / \mathrm{kg}$ body weight, and the factor $\mathrm{b}$ corrects for the influence of obesity on plasma volume [22]. Since plasma VLDL-TG is in a steady state throughout the study, VLDL-TG turnover rate $=$ VLDL-TG removal rate $=$ VLDL-TG secretion rate. This latter term will be used throughout the remainder of the paper.

\section{Statistical Analysis}

Results are expressed as the Mean \pm SEM, and Student's t-test was used for statistical comparisons.

\section{Results}

Mean plasma triglyceride levels were moderately, but significantly ( $\mathrm{p}<0.01)$, elevated in insulin-dependent diabetics compared to normal subjects (Table 2). However, the hypertriglyceridaemia was much greater in insulin-independent patients, and the mean value was significantly greater $(p<0.001)$ than in either the control or in the insulin-dependent groups. In addition, only four of 17 insulin-dependent diabetics had fasting plasma TG levels $>200 \mathrm{mg} / \mathrm{dl}$, as compared to 17 of 22 insulin-independent patients. 


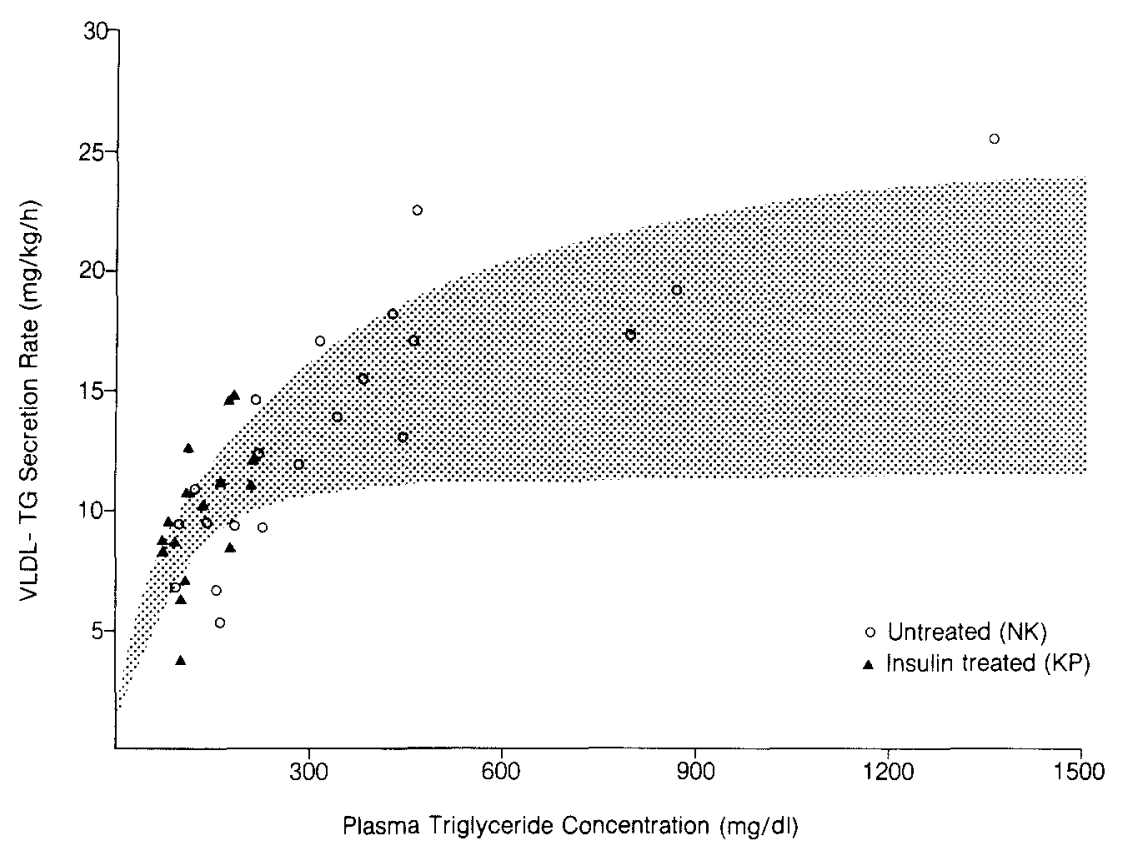

Fig. 1. Relationship between plasma triglyceride concentration and VLDL-TG secretion rate in diabetic patients. The shaded area represents the $95 \%$ confidence interval for the relationship between these two variables in 92 patients with normal fasting glucose and creatinine levels, studied in our laboratory
Thus, the incidence of hypertriglyceridaemia was greater in the latter group.

VLDL-TG secretion rates were also much greater $(\mathrm{p}<0.01)$ in insulin-independent than in insulindependent diabetics (Table 2). The mean VLDL-TG secretion rate of patients with insulin-dependent diabetes was also significantly $(p<0.05)$ greater than that observed in normal subjects.

The relationship between VLDL-TG secretion rate and plasma triglyceride concentration for all patients is seen in Figure 1. The shaded area in Figure 1 represents the $95 \%$ confidence interval for the relationship between VLDL-TG secretion rate and plasma triglyceride concentration in 92 euglycaemic subjects with normal renal function, and it is apparent that most diabetic patients appear either within or very close to the shaded area. These data support the hypothesis that hypertriglyceridaemia in these diabetic patients was due to an increase in VLDL-TG secretion rate, rather than to defective removal of VLDL-TG.

Figure 2 shows the fasting and postprandial plasma glucose response of the three groups. Fasting plasma glucose values (mg/dl) were $264 \pm 16,247 \pm$ 25 , and $85 \pm 1$ for the insulin-independent, insulindependent, and normal controls, respectively. Both diabetic groups reached a maximum glucose concentration two hours after beginning the $1200 \mathrm{~h}$ meal. The insulin-independent patients attained a maximum plasma glucose level of $407 \pm 25 \mathrm{mg} / \mathrm{dl}$, and the insulin-dependent patients reached a value of $418 \pm 32 \mathrm{mg} / \mathrm{dl}$. There was no significant difference

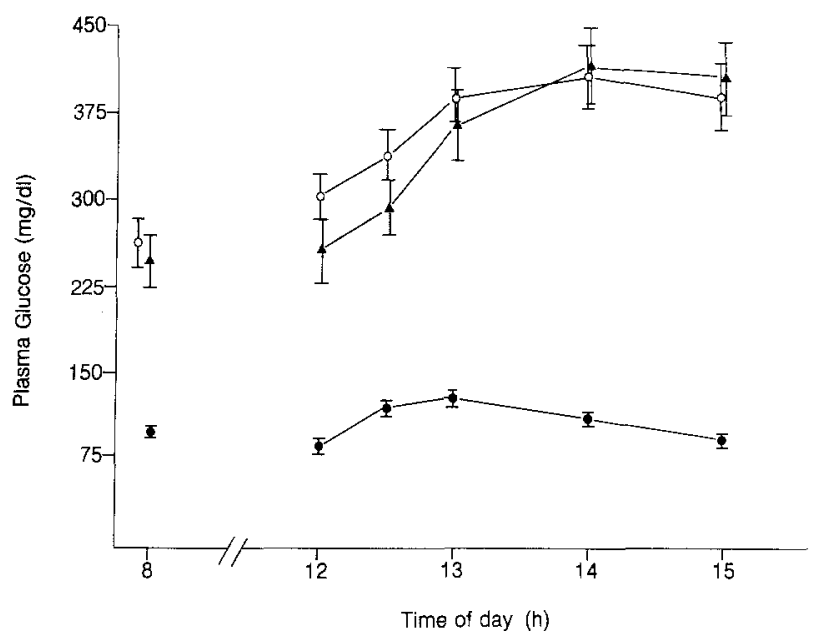

Fig. 2. Mean ( \pm SEM) fasting and postprandial glucose concentrations in the three groups of subjects. These measurements were made in each subject on three occasions during the study period, and the mean result in each patient was used to construct this figure

in plasma glucose concentrations, fasting or postprandial, between the two groups.

Plasma NEFA concentrations are shown in Figure 3. Fasting NEFA concentrations were significantly elevated in both insulin-independent $(\mathrm{p}<$ $0.001)$ and insulin-dependent $(\mathrm{p}<0.01)$ diabetics as compared to normal controls, although no difference existed between the two diabetic groups. Plasma NEFA concentrations fell after the $1200 \mathrm{~h}$ meal in the normal subjects, but remained persistently ele- 
vated in both diabetic groups, with no difference between them.

Fasting and postprandial insulin concentrations are illustrated in Figure 4. Although the mean levels were higher in the insulin-dependent diabetics than in the controls, this difference did not reach statistical significance due to the large variance in the diabetic subjects. This was also true when the logarithms of the insulin concentrations were used for the analysis, or when the data were analysed using non-parametric tests. Furthermore, fasting plasma insulin concentrations of the insulin-independent patients $(23 \pm 8 \mu \mathrm{U} /$ $\mathrm{ml}$ ) were not significantly different from those of the insulin-treated patients $(9 \pm 2 \mu \mathrm{U} / \mathrm{ml})$ and the normal controls $(12 \pm 3 \mu \mathrm{U} / \mathrm{ml})$. There was, however, striking difference in the response of the two diabetic groups to the meal. Despite a wide range of insulin values, insulin-independent diabetics were able to

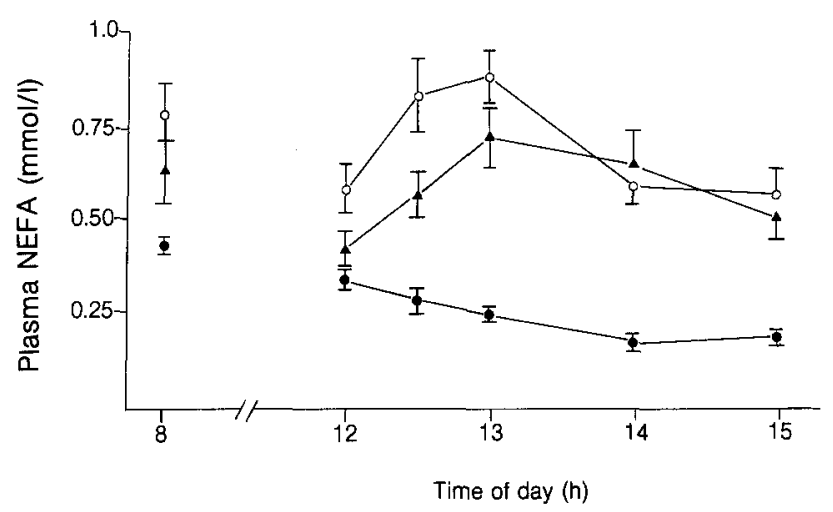

Fig. 3. Mean ( \pm SEM) fasting and postprandial NEFA concentrations in the three groups of subjects. These measurements were made in each subject on three occasions during the study period, and the mean result in each patient was used to construct this figure respond to the meal challenge by increasing insulin secretion. In contrast, insulin-treated patients had significantly lower insulin values than either normal or insulin-independent diabetic subjects, and there was no increase in response to the meal challenge.

\section{Discussion}

Recent reports have indicated that although hypertriglyceridaemia is relatively rare in insulin-treated patients with insulin-dependent diabetes [23, 24], it occurs frequently in patients with insulin-independent diabetes [25-27]. The cause for this difference between the two groups of patients is apparent from the data in Table 2 and Figure 1, which indicate that elevated triglyceride levels in the insulin-independent diabetics are secondary to increases in VLDL-TG secretion rates. Since the relationship between plasma triglyceride concentration and VLDL-TG secretion rate in the diabetic patients is quite similar to that seen in euglycaemic subjects, it appears that the removal of VLDL-TG from plasma is as efficient in the two groups of diabetic patients as it is in normoglycaemic subjects. The absence of any discernible evidence of a major defect in VLDL-TG removal in the diabetic patients raises a question as to the functional significance of the decreased levels of both postheparin plasma [13] and adipose tissue [14] lipoprotein lipase activity that have been noted in insulin-independent diabetics.

Patients with insulin-independent diabetes are both overweight and hyperinsulinaemic as compared to insulin-dependent diabetics, and we believe that both of these factors play a role in their increased VLDL-TG secretion rates and hypertriglyceridaemia. The insulin-treated patients were all receiving

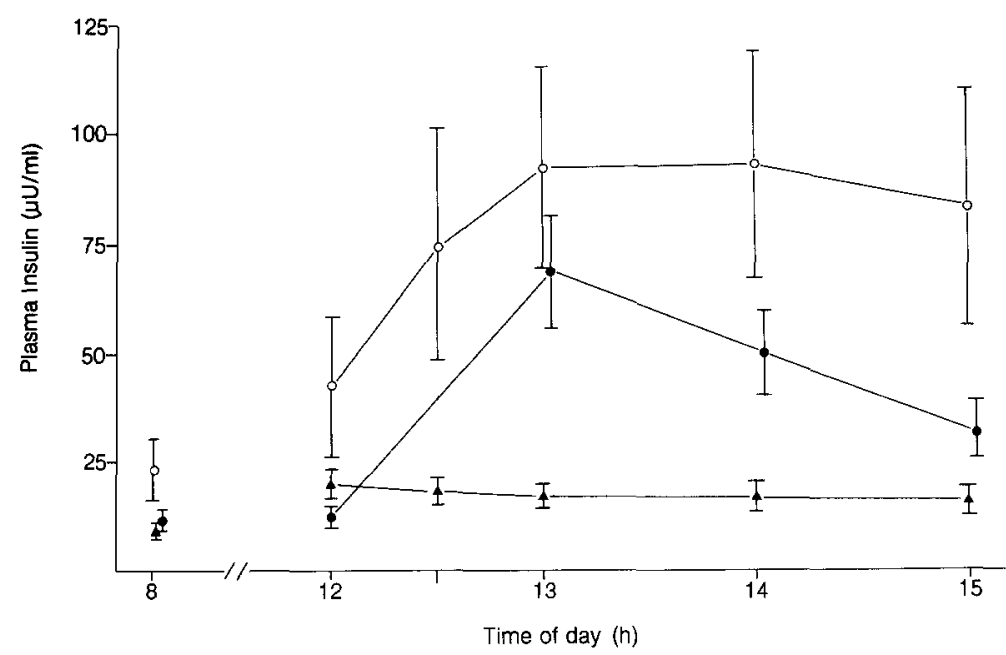

Fig. 4. Mean ( \pm SEM) fasting and postprandial free insulin concentrations in the three groups of subjects. These measurements were made in each subject on three occasions during the study period, and the mean result in each patient was used to construct this figure 
long-acting insulin, and their mean insulin levels were essentially unchanged throughout the day and significantly lower than that of the control subjects. In contrast, patients with insulin-independent diabetes responded to food by increasing insulin secretion, and their plasma insulin levels were comparable to those seen in the control subjects. Since the postprandial glucose levels of the two diabetic groups were essentially identical (Fig. 2), the higher insulin levels in the insulin-independent diabetics indicate that they were more insulin resistant than either the control population or the patients with insulindependent diabetes. It seems reasonable to assume that this was at least partly due to the presence of obesity, and that the increase in relative weight seen in patients with insulin-independent diabetes plays a significant role in the pathophysiology of their hypertriglyceridaemia [28].

Since the liver accounts for $90 \%$ of endogenous VLDL-TG secretion [29], it is likely that the hypertriglyceridaemia of the insulin-independent patients was secondary to increased hepatic VLDL-TG secretion. Previous studies have suggested that VLDL-TG secretion from perfused livers will increase as perfusate NEFA concentration increases [30]. It has also been shown that VLDL-TG secretion can be further stimulated, at any given perfusate NEFA concentration, by increasing perfusate insulin concentration [31-33]. Also, it has been demonstrated that perfused livers from hyperinsulinaemic animals will secrete more VLDL-TG than will livers from normoinsulinaemic animals $[33,34]$. Since the plasma insulin levels of the insulin-independent patients were not significantly greater than those of control subjects, it appears unlikely that hyperinsulinaemia per se can account for their hypertriglyceridaemia. On the other hand, they had significantly higher NEFA levels, both fasting and postprandially, and it seems reasonable to postulate that their hypertriglyceridaemia was due to the ability of the elevated plasma NEFA levels to increase hepatic VLDL-TG secretion. Although this explanation accounts for the difference in plasma triglyceride levels between insulin-independent diabetics and normal subjects, it does not explain why fasting triglyceride levels were so relatively low, in the insulin-treated patients. Since plasma NEFA concentrations were similar in both groups of diabetics, one might anticipate that they would be equally hypertriglyceridaemic. The fact that they weren't is most likely related to a permissive role, as contrasted to the regulatory role [31-34] that insulin plays in control of hepatic VLDL-TG secretion. Thus, the increment in VLDL-TG secretion from perfused liver that accompanied an increase in perfusate FFA concentration was greatly blunted when liv- ers were obtained from insulin-deficient animals [30]. In a similar fashion, it would appear that the day-long relative hypoinsulinaemia experienced by the insulin-treated patients limits the ability of their livers to increase hepatic VLDL-TG secretion. The result of this blunted response is that their VLDLTG secretion rates and plasma triglyceride levels were only moderately increased over those of normal subjects, in contrast to the more dramatic elevation noted in the insulin-independent patients. This formulation is consistent with both our experimental results and the available relevant data. It is also liable to direct experimental verification, and such efforts are now being carried out in our laboratory.

Acknowledgements. The authors would like to acknowledge the expert technical assistance of Jorene Moore, Kai-Yin Wu, and Raymond Ogata.

This work was supported in part by grants from the National Institutes of Health, HL 20397 and RR-70 from the General Clinical Research Centers Branch, and from the Research Services of the Veterans Administration.

\section{References}

1. Albrink MJ (1974) Dietary and drug treatment of hyperlipidemia in diabetes. Diabetes 23: 913-918

2. Reaven GM, Lerner RL, Stern MP, Farquhar JW (1967) Role of insulin in endogenous hypertriglyceridemia. $\mathrm{J}$ Clin Invest 46: 175 1756 -1767

3. Olefsky JM, Farquhar JW, Reaven GM (1974) Reappraisal of the role of insulin in hypertriglyceridemia. Am J Med 57: $551-560$

4. Bernstein RM, Davis BM, Olefsky JM, Reaven GM (1978) Hepatic insulin responsiveness in patients with endogenous hypertriglyceridemia. Diabetologia 14: 249-253

5. Bagdade JD, Porte Jr D, Bierman EL (1967) Diabetic lipemia: form of acquired fat induced lipemia. $N$ Engl $J$ Med 276: $427-433$

6. Reaven EP, Reaven GM (1974) Mechanisms for development of diabetic hypertriglyceridemia in streptozotocin-treated rats. $\mathrm{J}$ Clin Invest 54: 1167-1178

7. Basso LV, Havel RJ (1974) Hepatic metabolism of free fatty acids in normal and diabetic dogs. J Clin Invest 49: 537-547

8. Van Tol A (1977) Hypertriglyceridemia in the diabetic rat. Defective removal of serum very low density lipoproteins. Atherosclerosis 26: 117-128

9. Risser TP, Reaven GM, Reaven EP (1978) Intestinal very low density lipoprotein secretion in insulin-deficient rats. Diabetes 27: 902-908

10. Nikkilä EA, Kekki M (1973) Plasma triglyceride transport kinetics in diabetes mellitus. Metabolism 22:1-22

11. Kissebah AH, Adams PW, Wynn V (1974) Inter-relationship between insulin secretion and plasma free fatty acid and triglyceride transport kinetics in maturity onset diabetics and the effect of phenthylbiguanide (Phenformin). Diabetologia 10: $110-130$

12. Sigurdsson G, Nicoll A, Lewis B (1976) Metabolism of very low density lipoproteins in hyperlipidaemia: studies of apolipoprotein B kinetics in man. Eur J Clin Invest 6: 167-177

13. Nikkilä EA, Huttunen JK, Ehnholm C (1977) Postheparin plasma lipoprotein lipase and hepatic lipase in diabetes mel- 
litus: relationship to plasma triglyceride metabolism. Diabetes 26: $11-21$

14. Pykälistö OJ, Smith PH, Brunzell JD (1975) Determination of human adipose tissue lipoprotein lipase: effect of diabetes and obesity on basal- and diet-induced activity. J Clin Invest 56: 1108-1117

15. Kadish AH, Litle RL, Sternberg JC (1968) A new and rapid method for determination of glucose by measurement of rate of oxygen consumption. Clin Chem 14: 116-131

16. Akio N, Okabe H, Kita M (1973) A new colorimetric microdetermination of free fatty acids in serum. Clin Chim Acta 43: $317-320$

17. Wahlfeld AW (1974) Triglyceride determination after enzymatic hydrolysis. In: Bergmeyer HU (ed) Methods of enzymatic analysis, 2nd English ed. Academic Press, New York, p 1831-1835

18. Kuzuya H, Blix PM, Horwitz DL, Steiner DF, Rubenstein AH (1977) Determination of free and total insulin and C-peptide in insulin treated diabetics. Diabetes 26: 22-29

19. Desbuquois B, Aurbach GD (1971) Use of polyethylene glycol to separate free and antibody bound peptide hormones in radioimmunoassays. J Clin Endocrinol Metab 33: 732-739

20. Nikkilä EA, Kekki M (1971) Polymorphism of plasma triglyceride kinetics in normal human adult subjects. Acta Med Scand 190: 49-59

21. Farquhar JW, Gross RC, Wagner R, Reaven GM (1965) Validation of an incompletely coupled, two compartment, nonrecycling catenary model for the turnover of hepatic and plasma triglyceride in man. J Lipid Res 6: 119-134

22. Nikkilä EA, Kekki M (1972) Plasma triglyceride metabolism in thyroid disease. J Clin Invest 51: 2103-2114

23. Nikkilä EA, Hormila P (1978) Serum lipids and lipoproteins in insulin-treated diabetes. Demonstration of increased high density lipoprotein concentrations. Diabetes 27: 1078-1086

24. Moore WV, Knapp J, Kauffman RL, Perkins WG (1979) Plasma lipid levels in insulin-dependent diabetes mellitus. Diabetes Care 2: 31-34

25. Perrett AD, Rowe AS, Shahmanesh M, Allison SP, Hartog M (1974) Blood lipids in treated diabetics. Diabetologia 10: $115-118$
26. Maruhama Y, Abe R, Okuguchi F, Ohneda A (1977) Dietary intake and hyperlipidemia in controlled diabetic outpatients. Diabetes 26: 94-99

27. Paisey R, Elkeles RS, Hambley J, Magill P (1978) The effects of chlorpropamide and insulin on serum lipids, lipoproteins and fractional triglyceride removal. Diabetologia 15: 81-85

28. Olefsky JM, Reaven GM, Farquhar JW (1974) Effects of weight reduction on obesity: studies of carbohydrate and lipid metabolism. J Clin Invest 53: 64-76

29. Risser TR, Reaven GM, Reaven EP (1978) Intestinal contribution to secretion of very low density lipoproteins into plasma. Am J Physiol 234: E277-E281

30. Woodside WF, Heimberg M (1972) Hepatic metabolism of free fatty acids in experimental diabetes. Isr J Med Sci 8: 309-316

31. Letarte J, Fraser TR (1969) Stimulation by insulin of the incorporation of $\mathrm{U}-{ }^{14} \mathrm{C}$ glucose into lipids released by the liver. Diabetologia 5: 358-359

32. Tulloch BR, Dyal K, Fraser TR (1972) Increased lipid synthesis by liver slice in a superfusion system following raised glucose or insulin concentration. Diabetologia 8: 267-273

33. Topping DL, Mayes PA (1972) The immediate effects of insulin and fructose on the metabolism of the perfused liver. Biochem J 126: 295-311

34. Assimacopoulos-Jeannet J, Singh A, LeMarchand Y, Loten EG, Jeanrenaud B (1974) Abnormalities in lipogenesis and triglyceride secretion by perfused livers of obese-hyperglycaemic (ob/ob) mice: relationship with hyperinsulinemia. Diabetologia 10: 155-162

Received: June 7,1979

and in revised form: November 27, 1979

Gerald M. Reaven, M. D.

Veterans Administration Medical Center (182B)

3801 Miranda Avenue

Palo Alto, CA 94304

USA 